\title{
The Role of the Myers-Briggs Personality Type and Emotional Intelligence in Marital Satisfaction among Married Female Students at Tehran University
}

\author{
Galin Shirzad $^{1}$ \\ ${ }^{1}$ Department of Psychology, Sari Branch, Islamic Azad University, Sari, Iran \\ Correspondence: Galin Shirzad, Department of Psychology, Sari Branch, Islamic Azad University, Sari, Iran. Tel: \\ 98-91-2287-2494. E-mail: shirzad.galin@gmail.com
}

Received: December 7, 2015 Accepted: January 27, 2016 Online Published: February 24, 2016

doi:10.5539/gjhs.v8n10p50

URL: http://dx.doi.org/10.5539/gjhs.v8n10p50

\begin{abstract}
The present descriptive correlational study was conducted to predict the role of emotional intelligence and the Myers-Briggs personality type in marital satisfaction in married female students Tehran University in 2015. The study population consisted of all the married female students at Tehran University who visited Iran MBTI center between 22.04.2015 and 21.06.2015. A total of 140 students were selected as the study samples. Data were collected using the Myer-Briggs Type Indicator, the Bar-On Emotional Intelligence Questionnaire and the Enrich Marital Satisfaction Scale and were then analyzed in SPSS-20 using the multivariate regression analysis. The results obtained showed that emotional intelligence (interpersonal and intra-personal skills) and personality type (extraverted and structured) can predict marital satisfaction.
\end{abstract}

Keywords: marital satisfaction, emotional intelligence, personality type

\section{Introduction}

Marital life begins with the marriage of a man and a woman and their formation of a new family, and marital satisfaction is one of the factors that contribute to mental health in families. Marital satisfaction is taken to indicate a consistency between the individual's expectations of married life and his or her actual experiences of it. Marital satisfaction has different definitions, but the most useful one has been proposed by Hawkins, who described marital satisfaction as "the subjective feelings of happiness, satisfaction, and pleasure experienced by a spouse when considering all current aspects of his marriage" (Akbari et al., 2012). Studies conducted to determine the factors that affect the quality of marriage have proposed two perspectives: the intra-personal and the interpersonal perspectives (Coglin, Houston, \& Huts, 2000). Previous studies have shown that emotional intelligence and personality constitute intra-personal and personal variables that can affect marital life (Zeidner \& Cloche, 2013; Robins, Caspi, \& Moffitt, 2002; Bricker, 2005). Psychologists such as Carl Jung have studied and divided personality into different types in order to identify individuals' personality. Katharine Briggs and Isabel Briggs-Myers further developed Jung's personality types and proposed 16 different personality types, 4 dichotomies and 8 functions and developed a personality type test commonly known today as the Myers-Briggs Type Indicator. The main four personality dichotomies proposed by Myers-Briggs include the extraversion/introversion, sensing/intuition, thinking/feeling and judging/perception (Melancon \& Thompson, 1995; as cited in Rashidi, 2010). Despite the role of personality in predicting marital satisfaction by increasing and decreasing the frequency and severity of different interactive behaviors (Shahnazari et al., 2013; Hosseini et al., 2013; Kaor \& Sookhi, 2011), Kong (2010) study showed the couples showed no significant differences in marital satisfaction, positive affect, and conflict regulation according to similarities between spouses in Myers-Briggs Type Indicator. A limited number of studies have been conducted on the relationship between the Myer-Briggs personality type and marital satisfaction.

Another variable studied this research, is emotional intelligence. Emotional intelligence showing the individual's awareness of his emotions and how it affects his interpersonal relationships, and represents the individual's ability to recognize, assess and express emotions in a proper and compromising manner (Lucin, 2006). Bar-on (2006) believes that individuals with a high emotional intelligence are generally more successful in dealing with environmental pressures and demands and that emotional intelligence and cognitive intelligence equally affect 
general intelligence. Emotional intelligence plays a crucial role in marital compatibility because the quality of a couple's intimate relationship depends on their possession or lack of interactive skills, such as the skill of looking at problems from the spouse's point of view, effective conflict/problem-solving skills, an empathetic understanding of what the spouse has experienced and sensitivity and awareness about the spouse's needs (Raghibi \& Gharehchaei, 2013; Tabinda, 2013; Lee, 2011).

The purpose of the Myers-Briggs Type Indicator is to make the theory of psychological types described by C. G. Jung (1971) understandable and useful in people's lives. The essence of the theory is that much seemingly random variation in behavior is actually quite orderly and consistent, being due to basic differences in the way individuals prefer to use their perception and judgment. Perception involves all the ways of becoming aware of things, people, happenings, or ideas. Judgment involves all the ways of coming to conclusions about what has been perceived. If people differ systematically in what they perceive and in how they reach conclusions, then it is only reasonable for them to differ correspondingly in their interests, reactions, values, motivations, and skills. The MBTI instrument contains four separate indices. Each index reflects one of four basic preferences which, under Jung's theory, direct the use of perception and judgment. The preferences affect not only what people attend to in any given situation, but also how they draw conclusions about what they perceive.

Also Zeidner, Kloda and Matthews (2013) research data provide some support for the commonly held assumption that emotional intelligence plays a role in marital relationships. The study results of aliakbari (2012) showed that there is a significant positive correlation between emotional intelligence and marital satisfaction of women and their husbands. In addition, emotional intelligence of women and their spouses can explain $35 \%$ of women`s marital satisfaction variance and $6 \%$ of their husbands marital satisfaction variance.

Starting university life and making the transition from high school to the university comprise major changes in the life of a young adult. This critical period of life provides this age group with an opportunity for further learning and mental development (Friedlander, Reed, \& Shupak, 2007); for some students, this opportunity acts as a source of stress affecting different aspects of life. Married students have a more profound experience of the problems of this period. The rate of divorce has been steadily rising in recent years across the world and in Iran, where, according to the latest report by the National Statistics Organization, the year 2010 had the highest divorce rate of 124,741 , representing an increase of $8.8 \%$ over the last year (Alsharif, Bahrami, \& Fatehizadeh, 2012). Given the importance of marital satisfaction among students, the present study was conducted to understand whether the Myers-Briggs personality types and emotional intelligence have a role in marital satisfaction in university students. Hypotheses in present study were including:

- Emotional intelligence is a predictor of marital satisfaction among married female students.

- Myers-Briggs personality type is a predictor of marital satisfaction among married female students.

\section{Method}

\subsection{Participants}

The present study is basic in objectives and correlational in data collection. The study population examined consisted of all the married female students of Tehran University in 2015 who visited Iran MBTI center between 22.04.2015 and 21.06.2015 $(\mathrm{n}=230)$. Sample size was calculated as 148 using the Morgan table and based on the size of the study population. A list of visitors was prepared and sampling was conducted using the random selection method. The study inclusion criteria consisted only of living with one's spouse. Prior to completion of the questionnaires, the participants were briefed on the objectives of the study to the extent that the information provided did not affect the final results of the study. They then submitted their written consent for voluntary participation in the research and were asked to complete three questionnaires on which they had been briefed. They were also ensured of the confidentiality of their information. Some participants withdrew from the study; some submitted incomplete questionnaires and some were excluded from the study for different reasons, thereby reducing the sample size to 140 by the final stage of analysis.

\subsection{Instruments}

Myers-Briggs Type Indicator: The Myers-Briggs Type Indicator is a pen-and-paper test that can be performed individually or in group. This questionnaire has different forms that identify the individual's personality type as belonging to one of four dichotomies, including extraversion/introversion, sensing/intuition, thinking/feeling and judging/perception, three of which have been derived directly from Jung's theory and one of which was later added by Myers-Briggs. The present study uses the $\mathrm{G}$ form of the questionnaire, which contains 92 items ( 23 for each dichotomy) arranged as question statements and separate words. After completion, items are scored as 0 or 1 according to the scoring key. The maximum score obtained in each dichotomy scale is 23 . The studies 
conducted in other countries have shown a high correlation coefficient for the scores obtained on the MBTI form-G. In Iran, the reliability of the Myers-Briggs dichotomy scale was confirmed in a study conducted by Mahmoudian (2008) by calculating the Cronbach's alpha and using the test-retest method.

Bar-On Emotional Intelligence Questionnaire: The present study assessed participants' emotional intelligence using the standard Bar-On Emotional Intelligence Questionnaire, which was translated into Persian and normalized for the Iranian society by Raheleh Samou'ee et al. This questionnaire contained 117 items in its original form, but the number was later reduced to 90 after assessments, the elimination or modification of certain items and the redrafting of the entire items. Items were scored based on a 5-point Likert scale (from totally agree $=5$ to totally disagree $=1$ ) and some items were reverse-scored (from totally agree $=1$ to totally disagree $=5$ ). This questionnaire measures five components of emotional intelligence, including intra-personal skills, interpersonal skills, adaptation skills, stress control skills and general mood control skills. According to scientific studies, the validity coefficient needs to be at least 0.7 for questionnaires used in research and 0.9 for questionnaires used in clinical settings. The Cronbach's alpha measured for this scale was 0.93 (Khosrow Javid, 2008). The questionnaire can thus be used for different purposes and is acceptable in different settings. As questionnaires need to have reliability score of at least $80 \%$ to be reliable, this questionnaire can be considered a reliable tool with a score of 0.88 obtained through the odd/even split half method (Keyvanlu, 2010).

Enrich Marital Satisfaction Scale: The Enrich scale is available in both a 115-item and a 125 -item form and is used to assess potential problem areas or to identify strong fulfilling areas within a marriage (Olson \& Olson, 1997). The present study used a 47-item version of the scale. Responses are scored based on a 5-point Likert scale from 1 to 5 (totally agree, agree, neither agree nor disagree, disagree and totally disagree) and the sum of the scores obtained for each item shows the individual's degree of marital satisfaction. Some of the items are reverse scored. Researchers have grouped interrelated items of the scale and divided the 47 items into 11 components, including conventional response, marital satisfaction, personality issues, marital relationship, conflict resolution, financial management, leisure activities, sexual satisfaction, and marriage and raising children, interaction with the family and friends and religious prejudices. Only one of these components measures marital satisfaction (D. H. Olson \& A. Olson, 1997). The Cronbach's alpha coefficient was 0.48 for the marital satisfaction subscale of the Enrich scale as reported by Olson et al. (Salimi et al., 2009) and 0.92 and 0.95 for the whole scale as reported by Olson \& Olson and Soleimanian \& Navvabinejad (1994).

\section{Results}

According to the descriptive results of the study, the mean age of participants was 25.8 years (with a standard deviation of 2.28). Table 1 presents participants' mean scores $( \pm \mathrm{SD})$ in marital satisfaction, personality type and emotional intelligence.

Table 1. Mean and standard deviation of the study variables

\begin{tabular}{llll}
\hline Variable & Mean & Variance & Standard deviation \\
\hline Marital Satisfaction & 121.30 & 174.97 & 13.22 \\
Extraverted Type & 15.45 & 13.71 & 3.70 \\
Intuitive Type & 14.35 & 11.64 & 3.41 \\
Thinking Type & 13.71 & 19.01 & 4.36 \\
Structured Type & 16.05 & 21.83 & 4.67 \\
Intra-Personal Skills & 94.63 & 168.43 & 12.97 \\
Interpersonal Skills & 67.50 & 107.87 & 10.38 \\
Adaptation Skills & 35.61 & 37.90 & 6.15 \\
Stress Control Skills & 59.21 & 105.63 & 10.27 \\
General Mood Control Skills & 40.29 & 51.08 & 7.14 \\
\hline
\end{tabular}

As shown in Table 1, the mean scores obtained from participants' responses were 121.3 for marital satisfaction, 15.45 for the extraverted type, 14.35 for the intuitive type, 13.71 for the thinking type, 16.05 for the structured type, 94.63 for intrapersonal skills, 67.5 for interpersonal skills, 35.61 for adaptation skills, 59.21 for stress control skills and 40.29 for general mood control skills.

Table 2 shows the results obtained from the analysis of the variance of emotional intelligence and personality type in predicting marital satisfaction. 
Table 2. The analysis of the variance of emotional intelligence and personality type in predicting marital satisfaction

\begin{tabular}{|c|c|c|c|c|c|c|c|c|}
\hline Indicator/Variable & & $\begin{array}{l}\text { Sum of } \\
\text { Squares }\end{array}$ & $\begin{array}{l}\text { Degree of } \\
\text { Freedom }\end{array}$ & $\begin{array}{l}\text { Mean } \\
\text { Squares }\end{array}$ & $\mathrm{F}$ & $\mathrm{R}$ & $\mathrm{R} 2$ & Sig \\
\hline \multirow{3}{*}{$\begin{array}{l}\text { Extraverted } \\
\text { Type }\end{array}$} & Regression & 36534.21 & 1 & 3634.21 & 24.13 & 0.388 & 0.151 & 0.000 \\
\hline & Remainder & 20477.38 & 136 & 150.56 & & & & \\
\hline & Total & 24111.60 & 138 & & & & & \\
\hline \multirow{3}{*}{$\begin{array}{l}\text { Interpersonal } \\
\text { Skills }\end{array}$} & Regression & 5131.14 & 2 & 1565.57 & 18.24 & 0.461 & 0.213 & 0.000 \\
\hline & Remainder & 18980.45 & 135 & 140.59 & & & & \\
\hline & Total & 24111.60 & 137 & & & & & \\
\hline \multirow{3}{*}{ Structured Type } & Regression & 5751.15 & 3 & 1917.05 & 13.99 & 0.488 & 0.239 & 0.000 \\
\hline & Remainder & 18360.44 & 134 & 137.01 & & & & \\
\hline & Total & 24111.60 & 137 & & & & & \\
\hline
\end{tabular}

According to Table 2, in the first model, the correlation coefficient (R) is 0.388 when the extraverted type variable has entered the equation. In other words, the extraverted type explains $15 \%$ of the variance in marital satisfaction. In the second model, adding the interpersonal skills variable to the equation increased $\mathrm{R}$ to 0.461 . That is, the extraverted type and the interpersonal skills variables explain $21.3 \%$ of the variance in marital satisfaction overall. In the third model, adding the structured type variable to the equation further increased $\mathrm{R}$ to 0.488. In other words, the three variables explain $23.9 \%$ of the variance in marital satisfaction overall.

Table 3 shows the coefficients obtained for the independent variables (the extraverted type, interpersonal skills and the structured type) in predicting marital satisfaction。

Table 3. The coefficients of the independent variables (the extraverted type, interpersonal skills and the structured type) in predicting marital satisfaction

\begin{tabular}{llllll}
\hline Indicator/Variable & $\begin{array}{l}\text { Non-Standardized } B \\
\text { Coefficients }\end{array}$ & $\begin{array}{l}\text { Standard } \\
\text { Error }\end{array}$ & $\begin{array}{l}\mathrm{B} \\
\text { Coefficients }\end{array}$ & $\mathrm{T}$ & $\begin{array}{l}\text { Level of } \\
\text { Significance }\end{array}$ \\
\hline Constant & 72.003 & 8.312 & & 8.66 & 0.000 \\
Extraverted Type & 1.357 & 0.281 & 0.382 & 4.83 & 0.000 \\
Interpersonal & 0.310 & 0.098 & 0.244 & 3.17 & 0.002 \\
Skills & 0.468 & 0.220 & 0.165 & 2.12 & 0.035 \\
Structured Type & & & & & \\
\hline
\end{tabular}

According to the $\beta$ values obtained and the levels of significance, of all the three independent variables, the extraverted type variable had the highest share in predicting marital satisfaction while the structured type variable had the lowest.

\section{Conclusion}

According to the results, the extraverted type, interpersonal skills and the structured type predicted $23.9 \%$ of the overall variance in marital satisfaction. The results of a study conducted by Hosseini et al. (2013) showed a significant difference between normal couples and couples with conflicts in the dimensions of conscientiousness, extraversion and neuroticism. Agha-Mohammad-Hassani et al. (2012) found that emotional intelligence predicts $37 \%$ of the variance in marital satisfaction. In another study, Tabinda (2013) found a relationship between emotional intelligence and marital compatibility.

Extraversion appears to have a relationship with positive emotions such as vitality, optimism, love and intimacy. Highly extraverted individuals tend to easily express their emotions and feelings and have little restraint and are often active and sociable (Shahnazari et al., 2013). All these attributes have positive effects on the husband-wife relationship. Extraverted individuals are kind and sincere, have friendly relationships with others and appreciate positive emotions such as love and joy. Intimate relationships involve affection and warmth, self-disclosure, closeness and interpersonal dependence. Individuals who experience higher levels of intimacy are able to better present themselves in relationships and know how to express their needs more effectively to their partner or 
spouse. Couples with higher levels of intimacy may be better capable of dealing with relationship problems and changes and thus experience higher levels of marital satisfaction (Patrick et al., 2007). As extraverted individuals can easily express their emotions and show greater love and intimacy toward their spouse, they can be assumed to enjoy a higher marital satisfaction.

The relationship between extraverted-introverted tendencies and problem-solving styles can help explain the positive relationship of extraversion and the negative relationship of introversion to the quality of married life; that is, the relationship between the introverted tendency and the constructive problem-solving style is negative and significant, making the relationship between the extraverted tendency and the constructive problem-solving style positive and significant. Extraverted individuals are more confident in their ability to solve problems; there is therefore is a positive correlation between the extraverted personality and the problem-oriented coping style. According to studies, extraverted individuals use constructive problem-solving and problem-oriented coping styles and have a more desirable adaptive personality compared to introverted individuals. Some studies have shown that a couple's relationship is directly affected by each spouse's problem-solving style (Mahmoodi, 2011; Herring, Hewitt, \& Flat, 2003). It can therefore be assumed that, in marital relationships, the extraverted type can better overcome marital problems and conflicts by taking an active stance and using the problem-oriented coping style and therefore experiences a higher quality of marriage.

Individuals with higher emotional intelligence can better tolerate different sources of stress, whether arising from the family or their relationships, and can solve their problems more effectively because they are aware of their feelings and emotions, know how to manage the situation in a healthy constructive manner and possess emotional self-regulation, self-motivation, empathy and social skills. Compared to individuals with lower emotional intelligence, these individuals can establish better relationships with their spouse, better manage their time and responsibilities and have a better performance and a more effective, healthy and happy presence at home and in other areas of their life through the exchange of positive emotions with their environment. In line with this view, Gellman (2001) argues that emotional intelligence can help develop significant emotional relationships in different settings and harmonize emotions as a way of facilitating positive emotional exchange. Individuals with higher emotional intelligence are more involved with their spouse and experience a more intimate and loving relationship and therefore enjoy a higher marital satisfaction.

Couples tend to constantly experience different types of stress in their marital life and need to adjust to their stressful conditions and adapt to marital life; they therefore appear to need higher levels of flexibility in order to be able to simultaneously meet their own and their spouse's needs (and their spouse's family's needs too, in the case of a family-oriented country such as Iran). Flexible individuals tend to better adapt to the difficult conditions of married life by showing greater flexibility when faced with time constraints, deadlines, new experiences, variety-seeking tendencies, aesthetic desires, curiosity and independent judgments and therefore enjoy a greater marital satisfaction.

Given the positive and significant relationship between the extraverted personality type and the quality of marital life, it can be concluded that, through enabling warmer, friendlier and more intimate and open interactions with the spouse, extraversion helps facilitate marital compatibility and satisfaction and thus improves the quality of married life. As Kong (2010) study explained when nurses counsel couples, they should understand that differences in psychological type between spouses affect their marital relationship. In addition, nurses should educate couples on the characteristics of each type according to the couple's types and help them to understand each other.

Moreover, being structured in a marriage can be damaging depending on the degree of variability with which the couple is presented. Flexible types can better adapt to stress in their marital relationships. Possessing interpersonal skills as a component of emotional intelligence helps individuals establish more constructive and satisfying relationships with their spouse and enjoy an increased marital satisfaction. Also as Eslami et al. (2014) explained regarding the close relations between emotional intelligence and marital satisfaction, education centers such as universities, organizations and family clinics could use this variable in micro- and macro-social plans for improving the quality of the married people relations and promoting health of the families and the society.

Given the acquired nature of emotional intelligence, it is recommended for emotional intelligence training to also be included in premarital education programs as a means of increasing the prospects of a high marital satisfaction. Family and marriage therapists and counselors can use the findings of this study to develop measures through which they can help couples resolve their marital conflicts and can also help single individuals avoid unnecessary conflicts in their marriage through emphasizing the role of the personality type in choosing a spouse. 


\section{Acknowledgements}

The authors wish to express their gratitude to all the students who participated in this study and would also like to declare that they received no financial assistance from any organizations for conducting this research.

\section{Conflict of Interest}

The authors declare that there is no conflict of interests regarding the publication of this paper.

\section{References}

Agha-Hasani, P., Mokhtaree, M. R., Sayadi, A. R., Nazer, M., \& Mosavi, S. A. (2012). Study of Emotional Intelligence and Marital Satisfaction in Academic Members of Rafsanjan University of Medical Sciences. Journal of Psychology and Psychotherapy, 2(2), 1-5.

Akbari, E., Fahimi, S., Amiri, A., Azimi, Z., Khanli, R., \& Beirami, M. (2012). The role of emotional intelligence in anticipation of differentiation and marital satisfaction. Journal on the Psychological Knowledge, the First Year, (4), 68-78.

Aliakbari-Dehkordi, M. (2012). Relationship between emotional intelligence and marital satisfaction in couples. Journal of Behavioral Sciences, 6(2), 17-18.

Bar-on, R. (2006). The bar-on model of emotional intelligence skills development traning, program and student achievement and retention. Unpublished raw data, texas A \& M university-kingsville

Caughlin, J. P., Huston, T. L., \& Houts, R. N. (2000). How does personality matter in marriage. An examination of trait anxiety, interpersonal negativity, and marital satisfaction. Journal of Personality and Social Psychology, 78, 326-336. http://dx.doi.org/10.1037/0022-3514.78.2.326

Eslami, A. A., Hasanzadeh, A., \& Jamshidi, F. (2014). The relationship between emotional intelligence health and marital satisfaction: A comparative study. Journal of Education and Health Promotion, 21, 3-24. http://dx.doi.org/10.4103/2277-9531.127616

Friedlander, L., Graham, R., Naomi, S., \& Cribbie, R. (2007). Social Support, Self-Esteem, and Stress as Predictors of Adjustment to University among First-Year Undergraduates Washington. Journal of college student development, 48, 259-275. http://dx.doi.org/10.1353/csd.2007.0024

Haring, M., Hewitt, P. L., \& Flett, G. L. (2003). Perfectionism, Coping, and Quality of Intimate Relationships. Journal of Marriage and Family, 65, 143-158. http://dx.doi.org/10.1111/j.1741-3737.2003.00143.x

Hosseini, Z., Kholghi, Z., Jaberi, S., Siddiqui, A., Salehi, V., Tafvizi, M., et al. (2013). Compare couples conflicting personality traits and personality questionnaires 5 ordinary using Neo factor. Journal of Forensic Medicine, 4(1), 173-165.

Kaur, T., \& Sokhey, G. (2011). Personality, Emotional Intelligence and Marital Satisfaction of Violent and Non-Violent Couples. Journal of the Indian Academy of Applied Psychology, 37(1), 35-46.

Keivanlu, F., et al. (2010). Emotional intelligence and leadership styles. Sabzevar University of Medical Sciences Journal, 18(1), 47-54.

Khosro, J. M. (2003). Validity and reliability of the scale of emotional intelligence, shooting. MA thesis. Tarbiat Modarres University in Tehran.

Kong, S. S. (2010). Relationships between Myers-Briggs Type Indicator (MBTI) psychological type and marital satisfaction, divorce proneness, positive affect, and conflict regulation in clinic couples. Journal of Korean Academy and Nursing, 40(3), 336-48. http://dx.doi.org/10.4040/jkan.2010.40.3.336

Lee, V. E. (2011). The impact of alexithymia, emotional intelligence, marital values, and culture on relationship satisfaction (1st ed.). Charleston, SC: ProQuest UMI.

Lyusin, D. B. (2006). Emotional intelligence as a mixed construct. Journal of Russian and East European Psychology, 44(6), 54-68. http://dx.doi.org/10.2753/RPO1061-0405440604

Mahmoodi, F. (2011). The relationship between the coping styles with stress and marital satisfaction and their comparison among female student and normal population of women in Tehran. Procedia-Social and Behavioral Sciences, 30, 1301-1302. http://dx.doi.org/10.1016/j.sbspro.2011.10.252

Mahmoodian, D. A. (2008). Construction and Validation of view of the Myers-Briggs Type Inventory in Branch office employees. Career Advice Master Thesis, Faculty of Education and Psychology, University of Isfahan. 
Nasiri Z., Marashi, M., \& Raji, H. (2014). The Relationship between Emotional Intelligence and Marital Satisfaction: 10-Year Outcome of Partners from Three Different Economic Levels. Iranian Journal of Psychiatry, 9(4), 188-196.

Olson, D. H., \& Olson, A. (1997). Prepare Enrich Canada Program. Journal of Family Ministry, 11(4), 28-53.

Patrick, S., Sells, J. N., Giordano, F. G., \& Follerud, T. R. (2007). Intimacy, differentiation, and personality variables as predictors of marital satisfaction. The Family Journal, 15, 359-367. http://dx.doi.org/10.1177/ 1066480707303754

Raghibi, M., \& Ghareh-Chahi, M. (2013). Examine the relationship between emotional intelligence and spiritual intelligence in men and women on the verge of divorce and consistent. Journal of Women and Society (Issue A), 140-123.

Rashidi, J. (2010). Relationship between Myers-Briggs personality types with emotional intelligence. Family Counseling MA thesis, University of Allameh Tabatabai.

Robins, R. W., Caspi, A., \& Moffitt, T. E. (2002). It's not just who you're with, it's who you are: Personality and relationship experiences across multiple relationships. Journal of Personality, 70, 925-964. http://dx.doi.org/10.1111/1467-6494.05028

Salimi, H., Azad-Marzabadi, E., Amiri, M., \& Taghavi, M. R. (2009). Aspects of marital satisfaction among veterans' wives. Journal of New Thoughts on Education (winter), 4(4), 55-72.

Shahnazari, M., Salarian, Z. K., Vahidi, S. H., Javadpour, S. H., Alizadeh, N., Amini, F., et al. (2013). Survey the relationships between big five factor personalities and marital satisfaction in married Tehran's residents. Annals of Biological Research, 4(12), 129-132.

Sharif, M., Bahrami, F., \& Fatehizadeh, M. (2012). Effectiveness of an integrated approach in Isfahan divorced mothers on their compatibility. Journal of Counseling and Psychotherapy (Third Year), 11, 40-21.

Tabinda, J. (2013). Emotional intelligence as a predictor of marital adjustment to infertility. International Journal of Research Studies in Psychology, 2(3), 45-58.

Zeidner, M., \& Kloda, I. (2013). Emotional intelligence (EI), conflict resolution patterns, and relationship satisfaction: Actor and partner effects revisited. Personality and Individual Differences, 54(2), 278-283. http://dx.doi.org/10.1016/j.paid.2012.09.013

Zeidner, M., Kloda, I., \& Matthews, G. (2013). Does dyadic coping mediate the relationship between emotional intelligence (EI) and marital quality? Journal of Family Psychology, 27(5), 795-805. http://dx.doi.org/10. 1037/a0034009

\section{Copyrights}

Copyright for this article is retained by the author(s), with first publication rights granted to the journal.

This is an open-access article distributed under the terms and conditions of the Creative Commons Attribution license (http://creativecommons.org/licenses/by/3.0/). 